\title{
The effects of dorsal hippocampal lesions on reinforcement shifts
}

\author{
N. KRAMARCY, P. MIKULKA*, and F. FREEMAN \\ Old Dominion University, Norfolk, Virginia 23508
}

\begin{abstract}
This experiment attempted to clarify the effects of dorsal hippocampal lesions on a lick-rate response to reinforcement shifts. Rats received preshift solutions of either $4 \%$ or $32 \%$ sucrose and were then shifted to the opposite concentration. The results indicated (1) that Ss shifted to the increased concentration quickly adjusted to the control levels, and (2) a negative contrast effect (NCE) for both hippocampal and sham downshift groups. These results are in contrast to earlier failures to find a NCE in hippocampal Ss (Franchina \& Brown, 1971; Murphy \& Brown, 1970). It was proposed that the immediate feedback inherent in the licking response resulted in the standard contrast effect not found when longer ITIs are introduced.
\end{abstract}

The effect of hippocampal lesions has often been characterized as a loss of behavioral inhibition, resulting in increased activity levels (Teitelbaum \& Milner, 1963) and slower behavioral adjustment to reinforcement schedule changes (Clark \& Isaacson, 1965; Jarrard, 1965; Niki, 1965). Consistent with this, hippocampal rats fail to show any behavioral modification of a running response after shifts in incentives (Franchina \& Brown, 1971). However, these Ss do show the typical magnitude of reward effects during the preshift-acquisition phase. In contrast, Murphy and Brown (1970), using a licking response, found rapid behavioral adjustment to a decreased reward, but failed to find any evidence of the well-documented negative contrast effect (NCE; Black, 1968; Vogel, Mikulka, \& Spear, 1968). Murphy and Brown also found that the same Ss did not display any preference for varying sucrose concentrations in preference tests, but did respond appropriately during the preshift phase.

The present experiment was conducted to examine the effects of dorsal hippocampal lesions on lick rates after reward shifts. The lesions used in this study were considerably more localized than the complete hippocampal aspirations used by Franchina and Brown (1971) and Murphy and Brown (1970). Furthermore, this design used a symmetrical shift paradigm, while Murphy and Brown (1970) only shifted their Ss to lower reward levels. It might be expected that response differences due to hippocampal lesions might be symmetrical, as was found by Franchina and Brown (1971).

\section{METHOD}

\section{Subjects}

The Ss were 40 adult male hooded rats of the Long-Evans strain, approximately 180 days old at the start of the experiment.

\section{Surgery}

All Ss were anesthetized with an intraperitoneal injection of

*All reprint requests should be sent to the second author, Psychology Department, Old Dominion University, Norfolk, Virginia 23508. sodium pentobarbital $(50 \mathrm{mg} / \mathrm{kg})$, and 20 rats received hippocampal radio-frequency lesions using the bregma as the zero point. The lesion coordinates were: AP -3.4. ML 3.0, DV 3.5. The remaining 20 rats received sham operations consisting of opening the scalp and drilling two holes in the skull. All Ss were injected with $.1 \mathrm{cc}$ of atropine prior to surgery to reduce congestion. After surgery, the Ss were given a .10-cc injection of penicillin. A 10-day postoperative recovery period was allowed prior to testing.

\section{Histology}

At the end of testing, Ss were injected with an overdose of sodium pentobarbital and were perfused intracardially with $.9 \%$ saline followed by $10 \%$ Formalin. The brains were removed and stored in $10 \%$ neutral Formalin. Frozen sections were 60 microns thick and stained with cresyl violet.

\section{Apparatus}

The lesions were made with a Radionic radio-frequency lesion maker (Model R764). The test apparatus consisted of two Scientific Prototype Skinner boxes with drinking tubes calibrated in cubic centimeters, while Grason-Stadler drinkometers recorded the number of licks. A 70-dB (A scale) broadband white noise (re $0.0002 \mathrm{dyne} / \mathrm{cm}^{2}$ ) was used as a masking noise, which was presented through a speaker mounted in the ceiling of each box.

\section{Procedure}

All Ss were housed individually and maintained on ad lib food and water for 3 days prior to the beginning of deprivation. The food-deprivation regimen allowed the $S$ s a total daily intake of $10 \mathrm{~g}$ of Purina Lab Chow. The Ss had water available in the home cages throughout this study. The Ss receiving a $4 \%$ sucrose solution were given supplemental sugar with their food to control for the greater sugar intake of the $32 \% \mathrm{Ss}$. This supplement was the difference in the mean intakes of the $32 \%$ and $4 \%$ groups.

The Ss were allowed 5 days to adjust to the deprivation schedule prior to Day 1 of preshift training. In the preshift phase, the hippocampal and sham Ss were assigned randomly to either the $32 \%$ condition or the $4 \%$ condition. The preshift phase lasted for 18 days. Each day, the Ss were placed in the Skinner box for $5 \mathrm{~min}$ and the total number of licks was recorded. After each daily session, the Ss were given their food rations. On Day 19 of testing, the groups were factorially divided and either maintained on the same sucrose concentration or shifted to the other concentration. This procedure resulted in four groups $(\mathrm{N}=5)$ for each surgical condition: sham 32-32, sham 32-4, sham 4-4, sham 4-32, hippocampal 32-32, hippocampal 32-4, hippocampal 4-4, and hippocampal 4-32 (the first number 


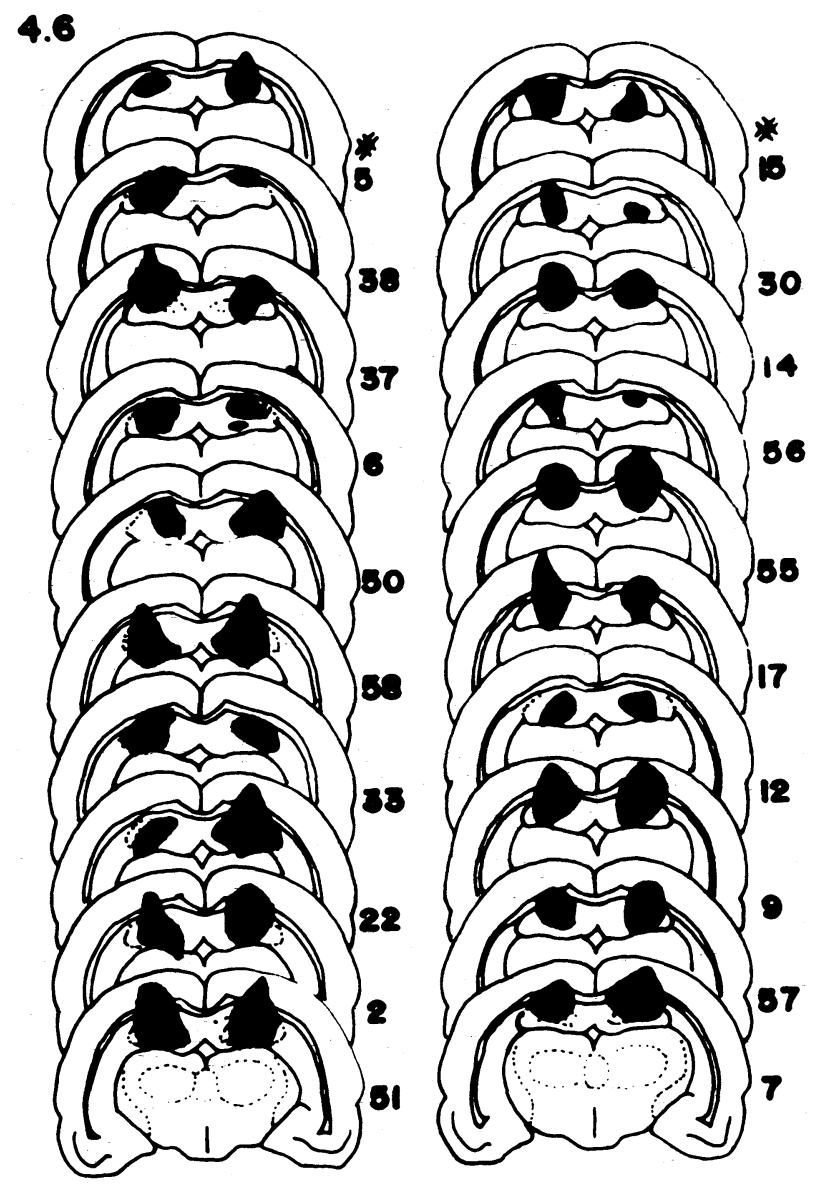

Fig. 1. Representative section through the dorsal hippocampus for all Ss.

designates the preshift concentration, and the second, the shift concentration).

\section{RESULTS \\ Histology}

Histological examination revealed bilateral damage to the dorsal hippocampus in the hippocampal Ss. Ventral-lateral aspects of the hippocampus were generally spared. Only minimal damage to the overlying cortex was observed (see Fig. 1). There was no correlation found in this study between size of hippocampal lesion and any of the dependent measures.

\section{Preshift}

An analysis of variance was performed on the last 4 days of preshift (Days 15-18). The main effect of concentration was significant $(F=4.02, d f=1 / 32, p=$ .05 ), with the $32 \%$ groups having a mean lick rate of 1,530 compared to 1,371 for the $4 \%$ groups. The main effects of operation and the "dummy" variable (to-be-shifted groups) were nonsignificant.
The effect of days $(F=5.03, \mathrm{df}=3 / 96, \mathrm{p}<.005)$ and the Days by Concentration interaction $(\mathrm{F}=2.98$, $\mathrm{df}=$ $3 / 96, p<.05)$ were significant. This was due to a general increase in-lick rates for all groups over the last 4 preshift days, but the $4 \%$ groups showed the greatest increases (see Fig. 2). None of the other interactions approached statistical significance. Due to extremely high lick rates of two Ss, the hippocampal $4-4$ group reached the level of the $32 \%$ groups on the last 4 days of preshift. However, with this exception, all other hippocampal groups and their respective sham groups correspond closely (see Fig. 2).

\section{Shift}

Simple factorial analyses of variance were performed on each day of the shift phase to track closely the behavioral effects of reward shifts.

The main effect of shift concentration was significant over all 5 days of shift, with the Ss on $32 \%$ sucrose having higher lick rates $(F s=38.90,26.62,24.17,12.54$, and $21.72 ; \mathrm{df}=1 / 32, \mathrm{p}<.001)$. The effect of operation did not approach significance for any of the shift days, nor did the Operation by Shift Concentration interaction. The interaction of Operation by Preshift Concentration failed to yield any consistent effects.

The Preshift by Postshift Concentrations interaction, which would reflect a nonsymmetrical adjustment to the reward shifts (i.e., the appearance of a NCE without a positive contrast effect, PCE) was significant over the

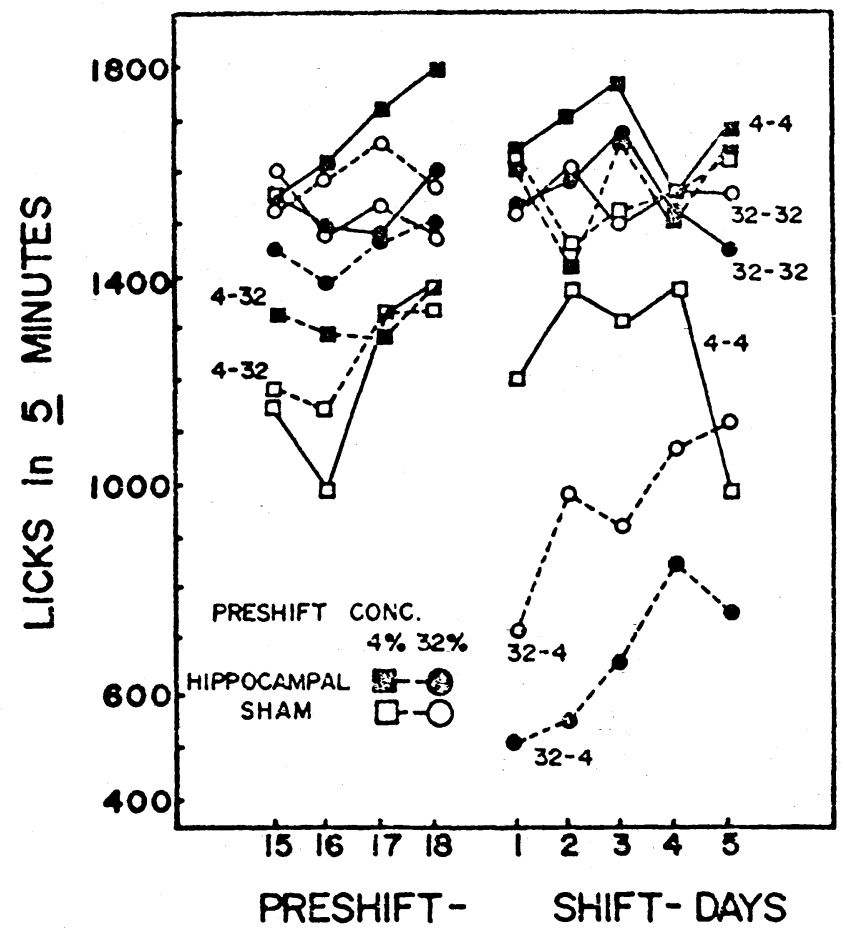

Fig. 2. The mean number of licks during the 5 -min test period over the last 4 days of preshift and the entire shift period. The dashed lines indicate the groups that were shifted, while the solid lines represent the control groups. 
first 4 days of shift $(F s=16.10,44.80,17.38,7.14 ; \mathrm{df}=$ $1 / 32, p<.01)$. The groups shifted to the higher sucrose concentration showed a rapid and appropriate adjustment to the level of the $32-32$ controls. Newman-Keuls comparisons support this by yielding nonsignificant differences between the upshift $4-32$ groups and their respective $32-32$ controls. Also, there were no differences between the hippocampal and sham upshift groups during this phase. In contrast, the groups shifted to the lower sucrose concentration evidenced a rapid drop in lick rates. The sham 32-4 Ss show a clear NCE with their lick rates significantly below those of their 4.4 controls over the first 3 days of shift (Newman-Keuls, $p<.01$ ), while by Day 5 of shift their performance was above the level of that of their controls $(\mathrm{p}<.05)$.

In interpreting the performance of the hippocampal 32.4 Ss, the hippocampal 4.4 group was not considered the appropriate control group because of its similarity to the hippocampal 32.32 group. However, since the preshift levels of the hippocampal $32-4$ group was very similar to the performance of the preshift sham 32-4 and sham 4-4 groups, the sham $4-4$ group was used as the reference group. The performance of the hippocampal 32.4 group is similar to that of the sham 32.4 group, with the hippocampal 32-4 Ss making significantly fewer licks than all other groups (with the exception of the sham $32-4$ group) over the 5 days of shift $(\mathrm{p}<.01)$. The hippocampal $32-4$ group was not different from the sham 32-4 group on Days 1-4 of shift but had a significantly lower lick rate on Day $5(\mathrm{p}<.01)$. Both downshift groups show strong NCEs, with the hippocampal Ss showing a more persistent depression in responding.

Finally, the Operation by Preshift by Shift Concentration interaction was significant over Days 1,2 , 3 , and $5(\mathrm{Fs}=5.05,8.51,47.4$, and $12.17 ; \mathrm{df}=1 / 32$, $\mathrm{p}<.03)$. This reflects the performance of the hippocampal 4-4 group, which performed at the level of the $32 \%$ shift groups throughout the shift phase, combined with the tendency toward a larger NCE for the hippocampal 32-4 group.

\section{DISCUSSION}

The primary object of this study was to examine the effect of localized hippocampal lesion on behavioral adjustment to reinforcement shift. The major research finding was that hippocampal Ss show a rapid and appropriate adjustment to increases in incentive and an undershooting of control levels following a reduction of incentive (a NCE). This result is the standard response pattern seen following reward shifts (Black, 1968; Vogel, Mikulka, \& Spear, 1968). These findings are not consistent with the results reported by Murphy and Brown (1970), using a very similar research design. Examination of their data showed a rapid decrease in lick rates after the shift from $32 \%$ to $4 \%$ and an apparent undershooting by the hippocampal Ss. However, this last effect was not statistically significant.
In marked contrast to both studies, Franchina and Brown (1971) found an almost complete absence of behavioral change following reward shifts. Two major differences between their study and the present one might account for the discrepancy. First, Franchina and Brown aspirated both cortex and dorsal and ventral hippocampus, and second, they used a running-speed response as their dependent variable. It is conceivable that with partial hippocampal lesions the Ss are not as insensitive to reinforcement contingency shifts as is typically found. However, the results of Murphy and Brown (1970) show that hippocampal Ss are extremely sensitive to reward shifts, since their lesions were identical to those of Franchina and Brown (1971).

The possibility remains that the task is critical to the observed differences. Using a consummatory response, feedback from licking is immediate and indicates the reward contingency, whereas the intertrial interval of a runway response $(6-8 \mathrm{~min})$ may allow the dissipation of reward aftereffects sufficiently in hippocampal animals to prevent the occurrence of appropriate behavioral adjustments. This assumption is given some support from studies in which the length of the ITI is varied. Extinction of a running response in a straight alley is retarded in hippocampectomized rats when long ITIs $(10 \mathrm{~min})$ but not when short ITIs $(10 \mathrm{sec})$ are used (Jarrard \& Isaacson, 1965; Jarrard, Isaacson, \& Wickelgren, 1964).

\section{REFERENCES}

Black, R. Shifts in magnitude of reward and contrast effects in instrumental and selective learning: $A$ reinterpretation. Psychological Review, 1968, 75, 114-126.

Clark, C., \& Isaacson, R. Effects of bilateral hippocampal ablation on DRL performance. Journal of Comparative \& Physiological Psychology, 1965, 59, 137-140.

Franchina, J., \& Brown, T. Reward magnitude shift effects in rats with hippocampal lesions. Journal of Comparative \& Physiological Psychology, 1971, 76, 365-370.

Jarrard, L. E. Hippocampal ablation and operant behavior in the rat. Psychonomic Science, 1965, 2, 115-116.

Jarrard, L. E., \& Isaacson, R. Hippocampal ablation in rats: Effects of intertrial interval. Nature, 1965, 207, 109-110.

Jarrard, L., Isaacson, R., \& Wickelgren, W. Effect of hippocampal ablation and intertrial intervals on runway acquisition and extinction. Journal of Comparative \& Physiological Psychology, 1964, 57, 442-444.

Murphy, H., \& Brown, T. Effects of hippocampal lesions on simple and preferential consummatory behavior in the rat. Journal of Comparative \& Physiological Psychology, 1970, 72, 404-415.

Niki, H. The effects of hippocampal ablation on the inhibitory control of operant behavior in the rat. Japanese Psychological Research, 1965, 7, 126-137.

Teitelbaum, H., \& Milner, P. Activity changes following partial hippocampal lesions in rats. Journal of Comparative \& Physiological Psychology, 1963, 56, 284-289.

Vogel, J., Mikulka, P., \& Spear, N. Effects of shifts in sucrose and saccharine concentration on licking behavior in the rat. Journal of Comparative \& Physiological Psychology, 1968, 66, 661-666.

(Received for publication September 30, 1972; revision accepted April 10,1973.) 